\title{
Dimensionamento de reservatório para aproveitamento de água de chuva: comparação entre métodos da ABNT NBR 15527:2007 e Decreto Municipal 293/2006 de Curitiba, PR
}

\author{
Sizing rainwater harvesting reservoirs: a comparison
} between methods of ABNT NBR 15527:2007 and of Municipal Decree 293/2006 from the city of Curitiba, PR

Stella Maris da Cruz Bezerra Departamento de Construção Civil Universidade Tecnológica Federal do Paraná

Av. Sete de Setembro, 3165 Curitiba - PR - Brasil CEP $80230-901$ Tel: (41) $3310-4608$ E-mail: sbezerra@utfpr.edu.br

Priscila de Christan Departamento de Construção Civil Universidade Tecnológica Federal do Paraná

priscila.christan@gmail.com

Celimar Azambuja Teixeira Departamento de Construção Civil Universidade Tecnológica Federal do Paraná

E-mail: celimar@utfpr.edu.br

Khosrow Farahbakhsh School of Engineering University of Guelph Albert A. Thornbrough Building Guelph - Ontario - Canada Tel. (519) 824-4120 E-mail: khosrowf@uoguelph.ca

Recebido em 27/04/10 Aceito em 10/10/10

\section{Stella Maris da Cruz Bezerra \\ Priscila de Christan \\ Celimar Azambuja Teixeira Khosrow Farahbakhsh}

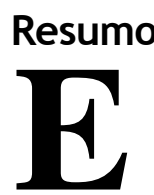

ste trabalho apresenta uma comparação entre os métodos de dimensionamento de reservatório de água de chuva propostos na NBR 15527:007 e no Decreto Municipal 293/2006, de Curitiba, PR. Para esta análise foram selecionadas cinco edificações que possuem sistema de captação e aproveitamento de água de chuva em funcionamento. Os resultados obtidos através dos dois métodos foram discrepantes. A fim de resultarem volumes coerentes com o aproveitamento de água de chuva, as equações do Decreto Municipal 293/2006 merecem uma revisão, para serem incluídas as considerações sobre índice pluviométrico, área de captação e demanda para a água de chuva armazenada. A utilização dos métodos apresentados na NBR 15527:2007 seria facilitada com ajustes de nomenclatura e inclusão de mais informações na apresentação das equações, em função da ambiguidade de denominação das variáveis. A decisão final sobre qual método mais indicado pode ser baseada na comparação dos volumes obtidos e na viabilidade em termos de área disponível e custo de construção do reservatório.

Palavras-chave: Água de chuva. Curitiba. Decreto Municipal No 293/2006. Dimensionamento. NBR 15527:2007. PURAE.

\section{Abstract}

This paper compares the methods for sizing rainwater reservoirs for non-potable uses provided by the Brazilian Standard NBR 15527/2007 and the Municipal Decree 293/2006 in the city of Curitiba, state of Parana (PR), in the south of Brazil. To pursue that objective, five rainwater harvesting systems located in buildings in the city of Curitiba were studied. The results obtained from those two methods varied significantly. In order to obtain volumes that are consistent with the harvesting of rainwater, the Municipal Decree equations should be revised in order to include rainfall data, roof size and the rainwater demands in their formulation. Standardization of the names of the variables is suggested for the methods described in NBR 15527/2007, as well as the inclusion of more information about its equations, since the existing ambiguities may lead to misunderstandings. In order to decide on the best method, one should compare the different results and evaluate the available area for the construction of the reservoir, as well as its cost.

Keywords: Curitiba. Municipal Decree 293/2006. NBR 15527:2007. PURAE. Rainwater. Sizing. 


\section{Introdução}

Em um sistema de captação e aproveitamento de água de chuva para fins não potáveis, o reservatório de armazenamento é geralmente o componente mais oneroso do sistema (AMORIM; PEREIRA, 2008; COHIM et al., 2008; COHIM; OLIVEIRA, 2009). Por esse motivo recomenda-se avaliar os diversos métodos de dimensionamento existentes, para então projetar a solução técnica e economicamente mais adequada para cada caso. Independentemente do método selecionado, o sistema para aproveitamento de água de chuva pode não suprir totalmente a demanda e necessitar de maior ou menor complementação com água da rede de abastecimento municipal. Por esse motivo, o projeto do reservatório deve incluir mecanismos para evitar a contaminação cruzada entre as fontes de abastecimento. Ou seja, a utilização de um sistema de captação de água de chuva deve ser baseada em análise da demanda a que será destinada, dos possíveis riscos sanitários, da adequação dos sistemas prediais e do correto dimensionamento do reservatório, para se evitar a implantação de projetos inadequados, que comprometam os aspectos positivos dessa fonte alternativa de água (COHIM et al., 2007). O índice pluviométrico da região, a área de captação de água de chuva e a previsão da demanda são parâmetros fundamentais nessa avaliação.

A Associação Brasileira de Normas Técnicas (ABNT) publicou em 2007 a NBR 15527, que trata do aproveitamento de água de chuva para fins não potáveis em áreas urbanas (ABNT, 2007). Naquele mesmo ano foi publicado o Decreto Municipal 212/2007 (CURITIBA, 2007) na cidade de Curitiba, capital do estado do Paraná, para efetivar o Decreto Municipal 293/2006 (CURITIBA, 2006), que trata do aproveitamento de água de chuva para fins não potáveis. Diversas outras cidades brasileiras também estão desenvolvendo legislações semelhantes. Com a finalidade de investigar métodos para o dimensionamento de reservatório de água de chuva para fins não potáveis, este trabalho apresenta um estudo de caso, para comparar os seis métodos de dimensionamento apresentados na NBR 15527:2007 e os dois métodos apresentados no Decreto Municipal 293/2006 de Curitiba.

\section{Aproveitamento de água de chuva}

O aproveitamento de água de chuva pode colaborar para economizar os recursos hídricos de qualidade superior e para prevenir a escassez da água potável nos sistemas de distribuição municipais. A água de chuva nos centros urbanos pode ser aproveitada em atividades que não necessitam água potável, como, por exemplo, na descarga de bacias sanitárias, na irrigação de jardins e na limpeza de pisos, equipamentos e carros. Outros usos também podem ser propostos, desde que atendam aos requisitos de qualidade e segurança sanitária, para os diversos fins e seus usuários. A necessidade do tratamento depende da qualidade da água de chuva armazenada e da finalidade a que se destina. A água de chuva também é aproveitada para fins potáveis em regiões onde se justifica essa necessidade.

Um projeto de captação, tratamento e uso de água de chuva é constituído de vários componentes, conforme bem detalhado em ANA (2006), não necessariamente sendo todos obrigatórios. Basicamente, o sistema é formado por área de captação ou área de contribuição, componentes de transporte constituídos de condutores horizontais, condutores verticais, calhas e reservatório (AMORIM; PEREIRA, 2008). Os componentes de transporte podem ser projetados conforme a NBR 10844:1989, intitulada "Instalações prediais de água pluviais" (ABNT, 1989). Essa norma fixa as exigências e critérios necessários ao projeto do sistema predial de água pluvial em coberturas e demais áreas associadas ao edifício, como terraços, pátios, quintais, entre outras áreas impermeáveis.

\section{Norma Brasileira ABNT NBR 15527:2007}

A NBR 15527 foi publicada pela ABNT em 2007 e é intitulada "Água de chuva - aproveitamento de cobertura em áreas urbanas para fins não potáveis - requisitos". Esta norma apresenta em seu anexo seis métodos para o dimensionamento do volume do reservatório de armazenamento da água de chuva: Método de Rippl, Método da Simulação, Método Azevedo Neto, Método Prático Alemão, Método Prático Inglês e Método Prático Australiano. De acordo com essa norma, fica a critério do projetista a decisão do método a ser utilizado, ou mesmo a utilização de algum outro procedimento de cálculo não apresentado na norma, desde que atendidos critérios técnicos, econômicos e ambientais.

Entre os métodos não incluídos no anexo da NBR 15527:2007 tem-se o método do máximo aproveitamento (MIERZWA et al., 2007; MORUZZI et al., 2008). Neste método o objetivo principal é possibilitar a redução da demanda de água potável, sem depender de alta confiabilidade de fornecimento de água de chuva, porém potencializando o uso desta durante o período 
chuvoso. Cohim et al. (2007) também apresentam um método para dimensionamento de reservatório, tendo como resposta verificar a taxa de atendimento à demanda anual para diferentes volumes de reservatórios, podendo acompanhar o balanço hídrico diário, com diferentes faixas de consumo e regimes pluviométricos. Outra avaliação interessante é feita pelo programa computacional Netuno, que determina o percentual de economia de água potável pelo aproveitamento de água de chuva, além da possibilidade de determinar o volume ideal do reservatório inferior (GHISI et al., 2009).

\section{Decreto municipal 293/2006 de Curitiba, PR}

A Prefeitura Municipal de Curitiba, capital do Paraná, publicou em 2003 a Lei Municipal $10.785 / 2003$, que propõe o Programa de Conservação e Uso Racional da Água nas Edificações (PURAE) (CURITIBA, 2003). Esse programa visa estabelecer medidas que induzam a conservação, o uso racional e a utilização de fontes alternativas para captação de água para todas as novas edificações do município de Curitiba. Entre as metas do programa incluem-se a captação e o aproveitamento da água de chuva para fins não potáveis. Após três anos da publicação daquela lei, entrou em vigor o Decreto Municipal 293/2006, para regulamentar o PURAE, quando também foram efetuadas algumas alterações em sua proposta inicial (CURITIBA, 2006). A obrigatoriedade em cumprir o PURAE foi efetivamente implantada em 2007, quando entrou em vigor o Decreto Municipal 212/2007, trazendo o novo Regulamento de Edificações do Município de Curitiba (CURITIBA, 2007). No Decreto Municipal 293/2006 são apresentados dois métodos para o dimensionamento do volume do reservatório de armazenamento da água de chuva, para aproveitamento em fins não potáveis, sendo um método para edificações habitacionais e outro para edificações comerciais.

\section{Método de pesquisa}

A partir do objetivo de apresentar uma comparação entre os métodos de dimensionamento de reservatório de água de chuva propostos na norma NBR 15527 (ABNT, 2007) e no Decreto Municipal 293/2006, foram selecionadas cinco edificações localizadas em Curitiba, PR, as quais possuem em funcionamento um sistema de captação e aproveitamento de água de chuva, para aproveitamento em fins não potáveis. As edificações selecionadas são três edifícios residenciais (Edifício A, Edifício B e Edifício C), uma edificação comercial (estacionamento e lavagem de veículos) e uma habitação unifamiliar. Cabe ressaltar que os reservatórios para armazenamento de água de chuva nessas edificações já estavam construídos, portanto o dimensionamento apresentado neste artigo é apenas investigativo.

\section{Edifício A}

O Edifício A possui quarenta e seis apartamentos e duas coberturas duplex, totalizando quarenta e oito unidades habitacionais. As áreas dos apartamentos variam entre 288 e $535 \mathrm{~m}^{2}$, com três ou quatro quartos por apartamento. A água da chuva é captada na cobertura do edifício, com área de contribuição de $300 \mathrm{~m}^{2}$, e conduzida através de calhas e condutores verticais para um reservatório de PVC (5.000 litros), que fica enterrado no jardim frontal do prédio. A água de chuva coletada é filtrada na entrada do reservatório e fica disponível para o uso em torneiras de acionamento restrito, dispostas no pavimento térreo, sendo o uso destinado a lavagem de pisos e a rega de jardins. $\mathrm{Na}$ ausência de chuva, esse reservatório recebe água potável do sistema municipal de abastecimento. As entradas de chuva e água potável foram projetadas de forma a evitar a contaminação cruzada.

\section{Edifício B}

O Edifício B é composto de duas torres com quarenta e cinco unidades habitacionais, sendo quatorze apartamentos com três quartos, e trinta e um apartamentos com dois quartos. A área dessas unidades varia de 126 a $350 \mathrm{~m}^{2}$. O sistema de captação coleta a água de chuva da cobertura, mas também do piso no pavimento térreo através de ralos, totalizando uma área de contribuição de 400 $\mathrm{m}^{2}$. A água de chuva coletada é armazenada em um reservatório de concreto armado, com capacidade de armazenamento de 10.000 litros, localizado no subsolo do prédio. Na entrada do reservatório existem grades metálicas para retenção de folhas ou de outros resíduos de maior dimensão. A água armazenada fica disponível para o uso em torneiras convencionais localizadas no pavimento térreo, sendo o uso destinado para a lavagem de pisos e rega de jardins. Na ausência de chuva esse reservatório também recebe água potável do sistema municipal de abastecimento, e as entradas de chuva e água potável foram projetadas de forma a evitar a contaminação cruzada. 


\section{Edifício C}

O Edifício C é composto de duas torres com sete andares. Cada torre possui um apartamento por andar, totalizando quatorze unidades habitacionais com quatro quartos e $639 \mathrm{~m}^{2}$ de área. A água de chuva é captada parcialmente da cobertura das duas torres, com uma área de contribuição de 500 $\mathrm{m}^{2}$. Depois segue através de calhas e condutores verticais até um único reservatório de concreto armado, localizado no subsolo de uma das torres, com capacidade de 38.000 litros. A água de chuva coletada é filtrada na entrada do reservatório inferior e então é bombeada para dois reservatórios superiores em cada torre, cada um com 8.600 litros. Estes reservatórios armazenam a água de chuva que é destinada para a descarga de bacias sanitárias dos apartamentos e para torneiras de acesso restrito no pavimento térreo, para a irrigação dos jardins e lavagem dos pisos. Da mesma forma que os demais edifícios, na ausência de chuva o reservatório recebe água potável do sistema municipal de abastecimento, e as entradas de chuva e água potável foram projetadas de forma a evitar a contaminação cruzada.

\section{Edificação comercial}

Na edificação comercial, que é um estacionamento e lavagem de veículos, a captação da água de chuva é feita na cobertura com área de contribuição de $125 \mathrm{~m}^{2}$. O reservatório de armazenamento é de PVC com capacidade de 5.000 litros. O tratamento dessa água é feito por filtração, apenas para retenção das partículas maiores. A água de chuva é destinada para a lavagem dos veículos.

\section{Habitação unifamiliar}

Na habitação unifamiliar a água de chuva é coletada da cobertura da edificação, com uma área de contribuição de $100 \mathrm{~m}^{2}$, e armazenada em um reservatório de PVC de 200 litros. A água coletada fica disponível através de uma torneira convencional localizada no próprio reservatório e é destinada para a lavagem de pisos e a rega de jardins. Essa água não sofre nenhum tipo de tratamento antes de ser utilizada.

\section{Constantes utilizadas nos estudos de caso}

Para a obtenção dos dados necessários nas equações para dimensionamentos apresentadas na NBR 15527 (ABNT, 2007) e no Decreto Municipal 293/2006, além da revisão bibliográfica, foram realizadas visitas técnicas nas edificações em questão e entrevistas com os respectivos responsáveis técnicos pelos projetos.

Neste artigo, para a apresentação dessas constantes e dos detalhes das metodologias de dimensionamento investigadas, selecionou-se o Edifício $\mathrm{B}$, pois suas características atendem às condições apresentadas nos métodos do anexo da NBR 15527 (ABNT, 2007). No caso do Edifício $C$, não foi possível a utilização dos métodos de Rippl, Simulação e Prático Australiano, porque o valor da demanda é maior que o volume de água de chuva aproveitável. Todos os demais detalhes e resultados para as outras edificações avaliadas estão descritos em Christan (2008).

\section{Definiç̧ão da demanda de água de chuva}

Em edificações comerciais, públicas ou residenciais é possível a utilização de água não potável em diversas atividades, desde que atendidas condições que garantam a segurança sanitária dos usuários e a qualidade necessária para as diversas finalidades. O Quadro 1 apresenta alguns exemplos de usos internos e externos da água, com base em residência norte-americana, para finalidades que poderiam ser abastecidas com água de chuva.

\begin{tabular}{|l|l|}
\hline \multicolumn{1}{|c|}{ Usos internos } & \multicolumn{1}{c|}{ Usos Externos } \\
\hline $\begin{array}{l}\text { A bacia sanitária é utilizada por uma } \\
\text { pessoa, em média, 4 a 6 vezes por dia. }\end{array}$ & $\begin{array}{l}\text { Em média um carro é lavado uma ou duas vezes por } \\
\text { semana, sendo gastos aproximadamente 150 litros de } \\
\text { água em cada lavagem. }\end{array}$ \\
\hline $\begin{array}{l}\text { A bacia sanitária consome, em média, } \\
6,8 \text { a 18 litros de água por descarga. }\end{array}$ & $\begin{array}{l}\text { Na irrigação de gramados ou na limpeza dos pisos, } \\
\text { gastam-se aproximadamente } 2 \text { litros } / \text { dia } / \mathrm{m}^{2} \text { de água. }\end{array}$ \\
\hline
\end{tabular}

Fonte: Tomaz (2005).

Quadro 1 - Alguns exemplos de usos internos e externos da água em residência norte-americana 
A partir dos dados do consumo potencial para água de chuva por equipamento e/ou atividade indicados no Quadro 1, foram feitas as seguintes considerações para o Edifício B:

(a) lavagem de $300 \mathrm{~m}^{2}$ de pisos diariamente, sendo 2 litros $/ \mathrm{dia} / \mathrm{m}^{2}$, que resultam em 600 litros/dia, ou $18 \mathrm{~m}^{3} / \mathrm{mês}$;

(b) rega de $100 \mathrm{~m}^{2}$ de jardins diariamente, sendo 2 litros/dia/ $\mathrm{m}^{2}$, que resultam em 200 litros/dia, ou 6 $\mathrm{m}^{3} / \mathrm{mês} ; \mathrm{e}$

(c) somando essas demandas, o volume necessário de água de chuva é de $24 \mathrm{~m}^{3} /$ mês.

Foram consideradas a lavagem de pisos e rega de jardins realizadas diariamente para resultar em demanda máxima. Neste artigo, conforme exposto acima, a demanda $\mathrm{D}=24 \mathrm{~m} 3 / \mathrm{mês}$ ou Danual = $288 \mathrm{~m} 3 /$ ano.

\section{Determinação da área de captação de água de chuva ou área de contribuição}

A determinação da área total de captação é uma etapa importante no desenvolvimento de um projeto para aproveitamento de água de chuva, pois irá influenciar no volume total coletado, assim como na qualidade da água a ser armazenada. Portanto, na área total deve ser considerado o somatório de todas as áreas de contribuição que serão direcionadas ao reservatório de armazenamento de água de chuva. O cálculo dessas áreas pode seguir os métodos indicados na NBR 10844 (ABNT, 1989). A norma brasileira para aproveitamento de água de chuva, NBR 15527 (ABNT, 2007), dispõe sobre os requisitos de captação apenas de coberturas, sendo estas situadas em áreas urbanas, mas vale ressaltar que em alguns casos a água de chuva pode também ser coletada de outras áreas, incluindo pisos impermeáveis. Para qualquer situação deve ser analisada a influência das características da área de coleta sobre a qualidade da água de chuva armazenada. No Edifício B a área de contribuição do sistema existente é parte da cobertura da edificação e do piso da área externa do pavimento térreo, com 400 m2. Assim, a área de captação A = $400 \mathrm{~m} 2$.

\section{Dados pluviométricos em Curitiba-PR}

Os índices pluviométricos do município de Curitiba para este estudo foram obtidos a partir da estação meteorológica da Superintendência de Desenvolvimento de Recursos Hídricos e Saneamento Ambiental (SUDERHSA), que é um órgão público do estado do Paraná. Os dados foram coletados para os anos de 1982 até 2007 e referem-se à Bacia do Rio Iguaçu, na estação denominada Prado Velho - PUC. Com base nesses dados, foram utilizadas as médias mensais e média anual histórica para o período de 1982 a 2007. Assim, Panual $=1.487,50 \mathrm{~mm}$ (média anual) e $\mathrm{Pt}$ (de janeiro a dezembro, em mm): 225,80; 186,60; 69,$20 ; 100,00 ; 106,20 ; 25,60 ; 41,60 ; 104,20$; 179,$20 ; 116,60 ; 170,40$ e 162,10 (médias mensais).

\section{Coeficiente de aproveitamento do escoamento superficial}

A partir de Tomaz $(2005,2010)$ pode-se dizer que o coeficiente de aproveitamento do escoamento superficial (indicado neste artigo pela variável $\mathrm{C}_{\mathrm{AP}}$ ) é referente à perda da água precipitada por interceptação, seja por evaporação, vazamentos ou lavagem do telhado, em função do material da superfície de escoamento, e da eficiência do sistema de captação de água de chuva. Esse coeficiente de aproveitamento do escoamento superficial é obtido pelo produto entre o coeficiente de escoamento superficial específico do material da área de captação (C), multiplicado por um fator de eficiência do sistema existente $\left(\eta_{\text {fator de captação }}\right)$. Dessa forma, o volume de água de chuva aproveitável é sempre menor do que o volume precipitado. O Método Prático Australiano para dimensionamento de reservatório de água de chuva, o qual está apresentado no anexo da NBR 15527 (ABNT, 2007), recomenda adotar o coeficiente de aproveitamento de escoamento superficial igual a 0,8 . Neste artigo também é adotado $\mathrm{C}_{\mathrm{AP}}=0,8$ para os demais métodos.

\section{Volume do reservatório existente}

Para o estudo de caso do Edifício B, detalhado neste artigo, o volume do reservatório que está construído naquela edificação foi estabelecido pelo projetista hidráulico em 10.000 litros. Esse volume é adotado como volume fixado inicial nos métodos por tentativas e denominado neste artigo $\mathrm{V}_{\mathrm{F}}=10$ $\mathrm{m}^{3}$.

\section{Volume de água de chuva aproveitável de acordo com a NBR 15527:2007}

A norma indica que o volume de água de chuva aproveitável depende dos fatores apresentados na Equação 1, em que a precipitação da chuva $(\mathrm{P})$ pode ser considerada a média anual, mensal ou diária.

$\mathrm{V}_{\mathrm{AP}}=\mathrm{P}_{\mathrm{t}} \times \mathrm{A} \times \mathrm{C} \times \eta_{\text {fator de captação }}$

Eq. 1 
$\mathrm{V}_{\mathrm{AP}}=$ volume de água de chuva aproveitável, podendo ser anual, mensal ou diária, em função da precipitação utilizada (litros);

$\mathrm{P}_{\mathrm{t}}=$ precipitação média da chuva no tempo $\mathrm{t}$ (anual, mensal ou diária) (mm);

$\mathrm{A}=$ área de captação $\left(\mathrm{m}^{2}\right)$;

$\mathrm{C}=$ coeficiente de escoamento superficial do material da cobertura (neste artigo adotado como 0,95 para o telhado de fibrocimento do Edifício B); e

$\eta_{\text {fator de captação }}=$ eficiência do sistema de captação, levando em conta a existência ou não de dispositivo de descarte de sólidos e desvio de escoamento inicial, que, segundo Tomaz (2010), é estabelecido na prática em 0,85 .

Dessa forma, e considerando a precipitação média anual, temos:

$\mathrm{V}_{\mathrm{AP}(\text { anual })}=1.487,5 \mathrm{~mm} \times 400 \mathrm{~m}^{2} \times 0,95 \times 0,85=$ 480.463 litros.

Assim, $\operatorname{VAP}($ anual $)=481 \mathrm{~m} 3$.

\section{Resultados e discussões}

Seguem os passos dos dimensionamentos pelos métodos que estão sendo investigados, ressaltando novamente que neste artigo são apresentados os detalhes apenas para o Edifício B, por atender a todas as condições de utilização dos diferentes métodos. Para os demais estudos de caso são indicados apenas os resultados para o comparativo entre os métodos. Os respectivos dados são encontradas em Christan (2008).

A NBR 15527 (ABNT, 2007) contém seis métodos para dimensionamento de reservatórios de água de chuva, apresentados em seu anexo e descritos a seguir. Para facilitar o entendimento das fórmulas e a comparação dos resultados, algumas variáveis usadas na norma tiveram a nomenclatura alterada neste artigo, mas sem modificar nenhum cálculo.

\section{Método de Rippl}

Neste método podem ser usadas as séries históricas mensais ou diárias de precipitação. No desenvolvimento desta pesquisa são utilizados os totais mensais. Seguem as equações para o Método de Rippl, utilizando a nomenclatura adaptada para este trabalho (Eq. 2 a Eq. 4).

$\mathrm{S}_{\mathrm{t}}=\mathrm{D}_{\mathrm{t}}-\mathrm{Q}_{\mathrm{t}}$

Eq. 2

Onde:

$\mathrm{S}_{\mathrm{t}}=$ volume de água de chuva armazenada no reservatório no tempo $\mathrm{t}\left(\mathrm{m}^{3}\right)$;
$\mathrm{D}_{\mathrm{t}}=$ demanda de água de chuva no tempo $\mathrm{t}\left(\mathrm{m}^{3}\right)$, sendo nesta pesquisa o volume da demanda constante, portanto na apresentação dos resultados é adotada a nomenclatura D; e

$\mathrm{Q}_{\mathrm{t}}=$ volume de água de chuva aproveitável no tempo $\mathrm{t}\left(\mathrm{m}^{3}\right)$, conforme a Equação 3, em que foi incluída a divisão por 1.000 para ajustar a unidade de volume.

$\mathrm{Na}$ norma aparece a indicação de demanda ou consumo no tempo $t\left(D_{t}\right)$, mas foi considerado aqui apenas como sendo a demanda, pois se entende que o consumo para a água de chuva não é medido no local.

$\mathrm{Q}_{\mathrm{t}}=\mathrm{C}_{\mathrm{AP}} \times \mathrm{P}_{\mathrm{t}} \times \mathrm{A} / 1.000$

Eq. 3

Onde:

$\mathrm{C}_{\mathrm{AP}}=$ coeficiente de aproveitamento do escoamento superficial (adotado 0,8 neste artigo);

$\mathrm{P}_{\mathrm{t}}=$ precipitação da chuva no tempo $\mathrm{t}(\mathrm{mm})$; e

$\mathrm{A}=$ área de captação $\left(\mathrm{m}^{2}\right)$.

A condição para a utilização desse método é que o somatório das demandas no tempo $\mathrm{t}$ deve ser menor do que o somatório do volume de água de chuva aproveitável no tempo $\mathrm{t}\left(\Sigma \mathrm{D}_{\mathrm{t}}<\Sigma \mathrm{Q}_{\mathrm{t}}\right)$. Para o Edifício B essa condição foi atendida, pois $\Sigma D_{t}=$ $288 \mathrm{~m}^{3} /$ ano e $\Sigma Q_{\mathrm{t}}=476 \mathrm{~m}^{3} /$ ano. O volume do reservatório de água de chuva receberá a nomenclatura $\left(\mathrm{V}_{\mathrm{R}}\right)$, onde:

$\mathrm{V}_{\mathrm{R}}=\Sigma \mathrm{S}_{\mathrm{t}}$, somente para valores $\mathrm{S}_{\mathrm{t}}>0$. Eq. 4

$\mathrm{O}$ procedimento de cálculo foi realizado conforme indicado na Tabela 1 .

Com base nessa metodologia, o volume dimensionado para o reservatório de água de chuva resultou em: VR = 28 m3 (Rippl).

\section{Método da simulação}

Neste método a norma NBR 15527 (ABNT, 2007) indica que duas hipóteses devem ser feitas:

(a) o reservatório está cheio no início da contagem do tempo t; e

(b) os dados históricos são representativos para as condições futuras.

Neste artigo a primeira hipótese não foi considerada e, ao contrário, fixou-se que o reservatório estava vazio no início da contagem do tempo t, para simular a situação de um reservatório recém-construído e, portanto, sem nenhuma quantidade de água de chuva armazenada. Assim, em janeiro, $S_{t-1}=0$. Seguem as equações para $o$ Método da Simulação:

$\mathrm{S}_{\mathrm{t}}=\mathrm{Q}_{\mathrm{t}}+\mathrm{S}_{\mathrm{t}-1}-\mathrm{D}_{\mathrm{t}}$

Eq. 5 


\begin{tabular}{|c|c|c|c|}
\hline \multirow[t]{2}{*}{ Meses } & $\begin{array}{l}\text { Precipitação da } \\
\text { chuva no tempo t }\end{array}$ & $\begin{array}{l}\text { Volume de água de chuva } \\
\text { aproveitável no tempo } \mathrm{t}\left(\mathrm{m}^{3}\right)(\mathrm{Eq} .3)\end{array}$ & $\begin{array}{l}\text { Volume de chuva armazenada no } \\
\text { reservatório no tempo t (Eq. 2) }\end{array}$ \\
\hline & $\mathbf{P}_{\mathrm{t}}(\mathbf{m m})$ & $Q_{t}\left(m^{3}\right)=C_{A P} \times P_{t} \times A / 1.000$ & $* S_{t}\left(m^{3}\right)=D-Q_{t}$ \\
\hline Janeiro & 225,8 & 72,26 & $-48,26$ \\
\hline Fevereiro & 186,6 & 59,71 & $-35,71$ \\
\hline Março & 69,2 & 22,14 & 1,86 \\
\hline Abril & 100,0 & 32,00 & $-8,00$ \\
\hline Maio & 106,2 & 33,98 & $-9,98$ \\
\hline Junho & 25,6 & 8,19 & 15,81 \\
\hline Julho & 41,6 & 13,31 & 10,69 \\
\hline Agosto & 104,2 & 33,34 & $-9,34$ \\
\hline Setembro & 179,2 & 57,34 & $-33,34$ \\
\hline Outubro & 116,6 & 37,31 & $-13,31$ \\
\hline Novembro & 170,4 & 54,53 & $-30,53$ \\
\hline Dezembro & 162,1 & 51,87 & $-27,87$ \\
\hline & & Volume do reservatório (Eq. 4) $V_{R}\left(\mathrm{~m}^{3}\right)$ & 28 \\
\hline
\end{tabular}

Tabela 1 - Dimensionamento do reservatório pelo Método de Rippl - Edifício B

\begin{tabular}{|c|c|c|c|c|}
\hline \multirow[t]{2}{*}{ Meses } & $\begin{array}{l}\text { Precipitação } \\
\text { da chuva no } \\
\text { tempo } t\end{array}$ & $\begin{array}{c}\text { Volume de água de } \\
\text { chuva aproveitável no } \\
\text { tempo t (Eq. 3) }\end{array}$ & $\begin{array}{c}\text { Volume de chuva } \\
\text { armazenada no reservatório } \\
\text { no tempo } t \text { menos } 1\end{array}$ & $\begin{array}{c}\text { Volume de chuva } \\
\text { armazenada no reservatório } \\
\text { no tempo } \mathrm{t}(\mathrm{Eq} .5)\end{array}$ \\
\hline & $\mathbf{P}_{\mathrm{t}}(\mathbf{m m})$ & $Q_{t}\left(m^{3}\right)=C_{A P} \times P_{t} \times A / 1000$ & $* \mathbf{S}_{(\mathrm{t}-1)}\left(\mathbf{m}^{3}\right)$ & $S_{t}\left(m^{3}\right)=D-Q_{t}$ \\
\hline Janeiro & 225,8 & 72,26 & 0,00 & 25,00 \\
\hline Fevereiro & 186,6 & 59,71 & 25,00 & 25,00 \\
\hline Março & 69,2 & 22,14 & 25,00 & 23,14 \\
\hline Abril & 100 & 32,00 & 23,14 & 25,00 \\
\hline Maio & 106,2 & 33,98 & 25,00 & 25,00 \\
\hline Junho & 25,6 & 8,19 & 25,00 & 9,19 \\
\hline Julho & 41,6 & 13,31 & 9,19 & 0,00 \\
\hline Agosto & 104,2 & 33,34 & 0,00 & 9,34 \\
\hline Setembro & 179,2 & 57,34 & 9,34 & 25,00 \\
\hline Outubro & 116,6 & 37,31 & 25,00 & 25,00 \\
\hline Novembro & 170,4 & 54,53 & 25,00 & 25,00 \\
\hline Dezembro & 162,1 & 51,87 & 25,00 & 25,00 \\
\hline \multicolumn{4}{|c|}{ Volume do reservatório $V_{R}\left(\mathrm{~m}^{3}\right)$} & 25 \\
\hline
\end{tabular}

Obs.: ${ }^{*} \mathrm{~S}_{\mathrm{t}-1}$ é considerado zero quando o reservatório está vazio ou quando $\mathrm{S}_{\mathrm{t}}$ é negativo no mês anterior.

Tabela 2 - Dimensionamento do reservatório pelo Método da Simulação - Edifício B

Onde:

$\mathrm{V}_{\mathrm{t}}=$ volume de água de chuva armazenada no reservatório no tempo $\mathrm{t}\left(\mathrm{m}^{3}\right)$;

$\mathrm{Q}_{\mathrm{t}}=$ volume de água de chuva aproveitável no tempo $\mathrm{t}\left(\mathrm{m}^{3}\right)$, conforme já apresentado na Eq. 3;

$\mathrm{S}_{\mathrm{t}-1}=$ volume de água de chuva armazenada no reservatório no tempo t menos $1\left(\mathrm{~m}^{3}\right)$; e

$\mathrm{D}_{\mathrm{t}}=$ demanda de água de chuva no tempo $\mathrm{t}\left(\mathrm{m}^{3}\right)$, sendo nesta pesquisa o volume da demanda constante, portanto na apresentação dos resultados é adotada a nomenclatura $\mathrm{D}$.

Para a utilização deste método adota-se um volume fixo para o reservatório no início da contagem do tempo t. Esse volume fixado é denominado neste artigo VF e deve atender à condição apresentada na Equação 6.

$0 \leq \mathrm{St} \leq \mathrm{VF}$

Eq. 6

Não está indicado na norma como definir o volume do reservatório (VR) a partir das equações apresentadas. Neste artigo considera-se que o volume do reservatório (VR) a ser escolhido será o que apresentar a maior confiança entre os volumes fixados nas tentativas (aqui indicado como VF). A primeira tentativa foi realizada com $\mathrm{VF}=10 \mathrm{~m} 3$, por ser o volume do reservatório existente. A partir desse valor, outros valores menores e maiores também foram testados. A confiança é estabelecida como a relação entre o período em que o reservatório atende à demanda (não precisa ser abastecido com outra fonte de água) e o período total investigado, que são 12 meses para este estudo de caso. Além da confiança verificou-se a eficiência do sistema, como sendo a relação entre o volume de chuva captada e o volume de chuva realmente utilizado, ou seja, o volume que não transbordou.

O procedimento de cálculo para o volume selecionado foi realizado conforme indicado na Tabela 2. 


\begin{tabular}{c|c|c}
\hline $\begin{array}{c}\text { Volume do reservatório } \\
\left(\mathbf{m}^{\mathbf{3}}\right)\end{array}$ & $\begin{array}{c}\text { Confiança do } \\
\text { sistema (\%) }\end{array}$ & $\begin{array}{c}\text { Eficiência do } \\
\text { sistema }(\boldsymbol{\%})\end{array}$ \\
\hline 10 & 83 & 59 \\
\hline 25 & 91 & 65 \\
\hline 27 & 100 & 66 \\
\hline 30 & 100 & 66 \\
\hline
\end{tabular}

Tabela 3 - Demais volumes testado no Método da Simulação - Edifício B

Além do volume indicado na Tabela $2\left(\mathrm{~V}_{\mathrm{F}}=25\right.$ $\mathrm{m}^{3}$ ), foram também efetuadas tentativas conforme apresentado na Tabela 3 .

Com base nesta metodologia, utilizando valores de confiança de $90 \%$ e considerando que a variação na eficiência não aumentou significativamente, o volume dimensionado para o reservatório de água de chuva ficou em: $V_{R}=25 \mathrm{~m}^{3}$ (Simulação).

\section{Método Azevedo Neto}

Neste método, também intitulado Método Prático Brasileiro (AMORIM; PEREIRA, 2008; COHIM et al., 2008), a NBR 15527 (ABNT, 2007) indica três definições para a variável $\mathrm{V}$, que são o volume de chuva, o volume de chuva aproveitável e o volume de água de chuva do reservatório. Neste artigo é feita uma diferenciação na nomenclatura da seguinte forma: o volume de chuva aproveitável é indicado por $\mathrm{V}_{\mathrm{AP}}$; e o volume do reservatório de água de chuva é indicado por $\mathrm{V}_{\mathrm{R}}$

A partir da equação apresentada para esse método entende-se que aquela resulta no volume a ser projetado para o reservatório $\left(\mathrm{V}_{\mathrm{R}}\right)$, quando considerado apenas 1 mês de seca $(\mathrm{T}=1)$ no período de 1 ano (Eq. 7). Para o município de Curitiba, situado na Bacia do Paraná (ou Bacia do Alto Iguaçu, na divisão estadual), não estão historicamente registrados números significativos de eventos de estiagem (ANA, 2009). Além disso, na Região Sul do Brasil as chuvas são bem distribuídas durante o ano (ANA, 2007). Dessa forma, a consideração para $\mathrm{T}=1$ é coerente.

$\mathrm{V}_{\mathrm{R}}=0,042 \times \mathrm{P}_{\text {anual }} \times \mathrm{A} \times \mathrm{T}$

Eq. 7

Onde:

$\mathrm{V}_{\mathrm{R}}=$ volume do reservatório de água de chuva (litros);

$\mathrm{P}_{\text {anual }}=$ precipitação da chuva média anual $(\mathrm{mm})$;

$\mathrm{A}=$ área de captação $\left(\mathrm{m}^{2}\right)$; e

$\mathrm{T}=$ número de meses de pouca chuva ou seco.

Então, $\mathrm{V}_{\mathrm{R}}=0,042 \times 1.487,5 \times 400 \times 1=24.990$ litros. Dessa forma, determinou-se o seguinte volume para o reservatório de água de chuva: $\mathrm{V}_{\mathrm{R}}=$ $25 \mathrm{~m}^{3}$ (Azevedo Neto).

\section{Método Prático Alemão}

A NBR 15527 (ABNT, 2007) indica que esse método considera o volume do reservatório de água de chuva como sendo $6 \%$ do menor valor entre:

(a) o volume anual do consumo, que aqui se considera como volume anual da demanda de água de chuva e indicado neste artigo como $\mathrm{V}_{\mathrm{D}}$; e

(b) o volume anual de chuva aproveitável, indicado neste artigo como $\mathrm{V}_{\mathrm{AP}(\text { anual })}$, a partir da fórmula da Eq. 1.

A condição desse método é expressa pela Equação 8 .

$\mathrm{V}_{\mathrm{R}}=\operatorname{mín}\left(\mathrm{V}_{\mathrm{D}} ; \mathrm{V}_{\mathrm{AP}}\right)$ x 0,06 (litros)

Eq. 8

A demanda mensal (D) foi estimada em $24 \mathrm{~m}^{3} / \mathrm{mês}$ (24.000 litros/mês), a qual, multiplicada pelos 12 meses do ano, resultou em $\mathrm{V}_{\mathrm{D}}=288.000$ litros/ano. $\mathrm{O}$ volume anual de chuva aproveitável anual, $\mathrm{V}_{\mathrm{AP}(\text { anual) }}$, foi obtido a partir da Equação 1 = 481.000 litros. Com esses dados e usando a Equação 8, encontra-se:

$\mathrm{V}_{\mathrm{R}}=$ mín $(288.000 ; 481.000) \times 0,06=17.280$ litros

Dessa forma, determinou-se o seguinte volume para o reservatório de água de chuva: $\mathrm{V}_{\mathrm{R}}=17 \mathrm{~m}^{3}$ (Prático Alemão).

\section{Método Prático Inglês}

Este método é semelhante ao de Azevedo Neto e apresenta a seguinte equação:

$\mathrm{V}_{\mathrm{R}}=0,05 \times \mathrm{P}_{\text {anual }} \times \mathrm{A}$

Eq. 9

Onde:

$\mathrm{V}_{\mathrm{R}}=$ volume do reservatório de água de chuva (litros);

$\mathrm{P}_{\text {anual }}=$ precipitação da chuva média anual $(\mathrm{mm})$; e

$\mathrm{A}=$ área de captação $\left(\mathrm{m}^{2}\right)$.

Então, $V_{R}=0,05$ x 1.487,5 x $400=29.750$ litros Dessa forma, foi determinado o seguinte volume para o reservatório de água de chuva: $\mathrm{V}_{\mathrm{R}}=30 \mathrm{~m}^{3}$ (Prático Inglês). 


\section{Método Prático Australiano}

Neste método o volume do reservatório $\left(\mathrm{V}_{\mathrm{R}}\right)$ é determinado por tentativas, para atender à demanda com confiança do sistema entre $90 \%$ e $99 \%$, conforme recomendação na NBR 15527 (ABNT, 2007). De acordo com as equações indicadas na norma, e considerando o período de 1 ano, que foi investigado nesses estudos de caso, o reservatório deve atender à demanda por no mínimo 11 meses ao ano, para obter confiança de 91\% (Equações 10 e 11).

Confiança do sistema $=\left(1-\mathrm{P}_{\mathrm{r}}\right)$

Eq. 10

Onde:

$\mathrm{P}_{\mathrm{r}}=$ falha do sistema (Eq. 11).

$\mathrm{P}_{\mathrm{r}}=\mathrm{N}_{\mathrm{r}} / \mathrm{N}$

Onde:

$\mathrm{N}_{\mathrm{r}}$ = número de meses em que o reservatório não atendeu à demanda, ou seja, quando o reservatório está vazio no fim do mês $\left(\mathrm{V}_{\mathrm{t}-1}=0\right)$, sendo $\mathrm{V}_{\mathrm{t}}$ (Eq. 12); e

$\mathrm{N}=$ número de meses considerado no cálculo, sendo indicado na NBR 15527 (ABNT, 2007) como geralmente 12 meses, portanto é o valor adotado neste artigo $(\mathrm{N}=12)$.

$\mathrm{V}_{\mathrm{t}}=\mathrm{V}_{\mathrm{t}-1}+\mathrm{Q}_{\mathrm{tI}}-\mathrm{D}_{\mathrm{t}}$

Onde:

$\mathrm{V}_{\mathrm{t}}=$ volume de água de chuva que está no reservatório no fim do mês;

$\mathrm{V}_{\mathrm{t}-1}=$ volume de água de chuva que está no reservatório no início do mês;

$\mathrm{Q}_{\mathrm{tI}}=$ volume de água de chuva aproveitável no mês $\left(\mathrm{m}^{3}\right)$, conforme a Equação 13, onde foi incluída a divisão por 1.000 para ajustar a unidade de volume; e

$\mathrm{D}_{\mathrm{t}}=$ demanda mensal para água de chuva $\left(\mathrm{m}^{3}\right)$, sendo nesta pesquisa o volume da demanda constante, portanto na apresentação dos resultados é adotada a nomenclatura D.

Para o primeiro mês, considera-se o reservatório vazio (ou seja, $\mathrm{V}_{\mathrm{t}-1}=0$ ). Além disso, quando $\left(\mathrm{V}_{\mathrm{t}-1}\right.$ $\left.+\mathrm{Q}_{\mathrm{tI}}-\mathrm{D}\right)<0$, então $\mathrm{V}_{\mathrm{t}}=0$.

$\mathrm{Q}_{\mathrm{tI}}=\mathrm{A} \times \mathrm{C}_{\mathrm{AP}} \times\left(\mathrm{P}_{\mathrm{t}}-\mathrm{I}\right) / 1.000$

Eq. 13

Onde:

$\mathrm{Q}_{\mathrm{II}}=$ volume de água de chuva aproveitável no mês, considerando interceptação $\left(\mathrm{m}^{3}\right)$;

$\mathrm{A}=$ área de captação $\left(\mathrm{m}^{2}\right)$;

$\mathrm{C}_{\mathrm{AP}}=$ coeficiente de aproveitamento do escoamento superficial (neste artigo adotado 0,8)

$\mathrm{P}_{\mathrm{t}}=$ precipitação da chuva média mensal $(\mathrm{mm})$; e

I = interceptação da água que molha as superfícies e perdas por evaporação, adotando-se $2 \mathrm{~mm}$, conforme indicado na NBR 15527 (ABNT, 2007).

O procedimento de cálculo foi realizado conforme indicado na Tabela 4.

Além do volume indicado na Tabela $4(\mathrm{VF}=17$ m3), foram também efetuadas tentativas, conforme apresentado na Tabela 5.

Com base nesta metodologia, utilizando valores de confiança de $90 \%$ e considerando que a variação na eficiência não aumentou significativamente, o volume dimensionado para o reservatório de água de chuva ficou em: VR = $17 \mathrm{~m} 3$ (Prático Australiano).

\begin{tabular}{|c|c|c|c|c|}
\hline \multirow[t]{2}{*}{ Meses } & $\begin{array}{l}\text { Precipitação da } \\
\text { chuva no tempo } t\end{array}$ & $\begin{array}{l}\text { Volume de água de } \\
\text { chuva aproveitável no } \\
\text { tempo t (Eq. 13) }\end{array}$ & $\begin{array}{l}\text { Volume de chuva armazenada } \\
\text { no reservatório no início do mês }\end{array}$ & $\begin{array}{l}\text { Volume de chuva armazenada } \\
\text { no reservatório no fim do mês } \\
\text { (Eq. 12) }\end{array}$ \\
\hline & $\mathbf{P}_{\mathbf{t}}(\mathbf{m m})$ & $\begin{array}{c}\mathbf{Q}_{\mathrm{tI}}\left(\mathbf{m}^{3}\right)=\mathbf{A} \times \mathbf{C}_{\mathrm{AP}} \times\left(\mathbf{P}_{\mathrm{t}}-\right. \\
\text { I) } / \mathbf{1 0 0 0}\end{array}$ & $\mathbf{V}_{(\mathbf{t}-1)}\left(\mathbf{m}^{3}\right)$ & $V_{t}\left(m^{3}\right)=V_{(t-1)}+Q_{t I}-D$ \\
\hline Janeiro & 225,8 & 71,62 & 0,00 & 17,00 \\
\hline Fevereiro & 186,6 & 59,07 & 17,00 & 17,00 \\
\hline Março & 69,2 & 21,50 & 17,00 & 14,50 \\
\hline Abril & 100 & 31,36 & 14,50 & 17,00 \\
\hline Maio & 106,2 & 33,34 & 17,00 & 17,00 \\
\hline Junho & 25,6 & 7,55 & 17,00 & 0,55 \\
\hline Julho & 41,6 & 12,67 & 0,55 & 0,00 \\
\hline Agosto & 104,2 & 32,70 & 0,00 & 8,70 \\
\hline Setembro & 179,2 & 56,70 & 8,70 & 17,00 \\
\hline Outubro & 116,6 & 36,67 & 17,00 & 17,00 \\
\hline Novembro & 170,4 & 53,89 & 17,00 & 17,00 \\
\hline Dezembro & 162,1 & 51,23 & 17,00 & 17,00 \\
\hline & & & olume do reservatório $\mathbf{V}_{\mathbf{R}}\left(\mathrm{m}^{3}\right)$ & 17 \\
\hline
\end{tabular}

Obs.: * $\mathrm{V}_{\mathrm{t}-1}$ é considerado zero quando o reservatório está vazio ou quando $\mathrm{V}_{\mathrm{t}}$ é negativo no mês anterior. Tabela 4 - Dimensionamento do reservatório pelo Método Prático Australiano - Edifício B 


\begin{tabular}{c|c|c}
\hline $\begin{array}{c}\text { Volume do reservatório } \\
\left(\mathbf{m}^{\mathbf{3}}\right)\end{array}$ & $\begin{array}{c}\text { Confiança do } \\
\text { sistema (\%) }\end{array}$ & $\begin{array}{c}\text { Eficiência do } \\
\text { sistema }(\boldsymbol{\%})\end{array}$ \\
\hline 10 & 83 & 60 \\
\hline 17 & 91 & 63 \\
\hline 25 & 92 & 66 \\
\hline 30 & 100 & 68 \\
\hline
\end{tabular}

Tabela 5 - Demais volumes testados no Método Prático Australiano - Edifício B

Fonte: Curitiba (2006).

\begin{tabular}{c|c}
\hline Quantidade de quartos & Consumo (litros/dia) \\
\hline 1 (um) & 400 \\
\hline 2 (dois) & 600 \\
\hline 3 (três) & 800 \\
\hline 4 (quatro) ou mais & 1.000 \\
\hline
\end{tabular}

Tabela 6 - Consumo diário de água de chuva por quarto (litros/dia)

\section{Método do decreto municipal 293/2006 para edificações habitacionais}

No Decreto Municipal 293/2006, de Curitiba-PR, são indicadas duas equações para o dimensionamento do volume do reservatório, uma destinada a edificações habitacionais e outra para comerciais. Em todos os casos fica estabelecido um volume mínimo de 500 litros.

O dimensionamento do reservatório de água de chuva nas edificações habitacionais é indicado a partir da Equação 14, em que a nomenclatura $\mathrm{V}$ foi substituída por $\mathrm{V}_{\mathrm{R}}$.

$\mathrm{V}_{\mathrm{R}}=\mathrm{N}_{\mathrm{u}} \times \mathrm{C}_{\mathrm{d}} \times \mathrm{d}_{\mathrm{r}} \times 0,25$

Eq. 14

Onde:

$\mathrm{V}_{\mathrm{R}}=$ volume do reservatório de água de chuva (litros);

$\mathrm{N}_{\mathrm{u}}$ = número de unidades habitacionais (quando edifícios de habitação coletiva);

$\mathrm{C}_{\mathrm{d}}=$ consumo diário de água de água de chuva (litros/dia), conforme a Tabela 6; e

$\mathrm{d}_{\mathrm{r}}=$ número de dias de reserva $=2$ (estabelecido no Decreto Municipal 293/2006).

Então, VR $=(14$ unidades de 3 quartos $\times 800+31$ unidades de 2 quartos x 600) x 2 × 0,25=14.900 litros. Dessa forma, determinou-se o seguinte volume para o reservatório de água de chuva: VR $=15 \mathrm{~m} 3$ (Decreto Municipal Curitiba, para edificação residencial).

\section{Método do decreto municipal 293/2006 para edificações comerciais}

O dimensionamento do reservatório de água de chuva nas edificações comerciais é indicado a partir da Equação 15.
$\mathrm{V}=\mathrm{Ac} \times 0,75$

Eq. 15

Onde:

$\mathrm{V}=$ volume do reservatório de água de chuva (litros); e

Ac $=$ área total computável da edificação $\left(\mathrm{m}^{2}\right)$.

Lembra-se que neste artigo estão apresentados os cálculos apenas para o Edifício $\mathrm{B}$, que é residencial; portanto, o método do decreto para edificação comercial não se aplica. Vale destacar que os resultados do estudo de caso da edificação comercial, bem como para os demais residenciais, estão descritos em Christan (2008).

\section{Resumo dos resultados e considerações finais}

A Tabela 7 mostra os volumes dos reservatórios obtidos através dos diferentes métodos, para todos os estudos de caso.

De forma geral, os resultados foram discrepantes entre os diferentes métodos. A melhor aproximação ocorreu para o Edifício B, onde o maior volume obtido $\left(30 \mathrm{~m}^{3}\right)$, pelo Método Prático Inglês, foi da ordem de duas vezes o menor volume obtido $\left(15 \mathrm{~m}^{3}\right)$, pelo Método do Decreto Municipal 293/2006. O caso mais extremo ocorreu para a edificação comercial, onde a diferença foi da ordem de 100 vezes, pois o Método de Rippl resultou em aproximadamente $20 \mathrm{~m}^{3}$, e o Método do Decreto Municipal 293/2006 resultou em apenas $0,2 \mathrm{~m}^{3}$. 


\begin{tabular}{|c|c|c|c|c|c|}
\hline \multicolumn{6}{|c|}{ Volume dos reservatórios $\left(\mathrm{m}^{3}\right)$} \\
\hline \multirow[b]{2}{*}{ Métodos } & \multicolumn{5}{|c|}{$\begin{aligned} \text { Edificações } \\
\end{aligned}$} \\
\hline & Edifício A & Edifício B & Edifício C & $\begin{array}{l}\text { Edificação } \\
\text { comercial }\end{array}$ & $\begin{array}{l}\text { Habitação } \\
\text { unifamiliar }\end{array}$ \\
\hline Rippl & 55 & 28 & $334^{1}$ & 18 & 18 \\
\hline Simulação & 36 & 25 & $14^{2}$ & 19 & 15 \\
\hline Azevedo Neto & 19 & 25 & 31 & 8 & 6 \\
\hline Prático Alemão & 19 & 17 & 36 & 8 & 6 \\
\hline Prático Inglês & 22 & 30 & 37 & 9 & 7 \\
\hline Prático Australiano & 38 & 25 & $14^{2}$ & 20 & 15 \\
\hline $\begin{array}{c}\text { Decreto 293/2006 - } \\
\text { Edificação residencial }\end{array}$ & 24 & 15 & 7 & NA & 0,5 \\
\hline $\begin{array}{c}\text { Decreto 293/2006 - } \\
\text { Edificação comercial } \\
\end{array}$ & NA & NA & NA & 0,2 & NA \\
\hline
\end{tabular}

Campos et al. (2007), Mierzwa et al. (2007) e Amorim e Pereira (2008) comentam que Rippl é o método mais utilizado, porém, por ter sido desenvolvido inicialmente para a regularização de vazão, geralmente resulta em grandes reservatórios. Neste estudo isso não foi constatado. Por outro lado, para o edifício com maior demanda de água de chuva, onde esta é utilizada em descarga de bacias sanitárias (Edifício C), os Métodos de Rippl, Simulação e Prático Australiano não puderam ser testados, pois as condições impostas naqueles métodos não tiveram como ser atendidas. Para os demais estudos de caso, os resultados foram próximos para o Método da Simulação e Prático Australiano, pois a metodologia de cálculo é semelhante. No Método de Azevedo Neto e no Método Prático Alemão os resultados se enquadram nos menores volumes entre os métodos apresentados na NBR 15527 (ABNT, 2007). Em quatro dos cinco estudos de caso, na comparação entre todos os métodos avaliados neste artigo, os menores valores foram obtidos pelo Método do Decreto Municipal 293/2006, tanto para edificações residenciais quanto comerciais.

\section{Comentários sobre o decreto municipal 293/2006}

Em relação ao Método do Decreto Municipal 293/2006 para edificação comercial, a equação considera o volume do reservatório como sendo $75 \%$ da área total computável da edificação, mas nenhum parâmetro relacionado ao índice de precipitação pluviométrica, nem a demanda para a água de chuva, nem a área de captação. Da mesma forma, para edificações residenciais a equação é formulada a partir do número de quartos da unidade residencial, levando em consideração valores de consumo per capita de água potável e não considerando parâmetros relacionados à demanda para água de chuva. Comparando os resultados das equações do Decreto Municipal 293/2006 com os dos métodos da NBR 15527 (ABNT, 2007), fica evidente a necessidade de mais investigações acerca das fórmulas daquele decreto e provavelmente sua revisão, a fim de serem incluídas as considerações sobre o índice pluviométrico, a área de captação e a demanda para a água de chuva armazenada.

\section{Comentários sobre a NBR 15527:2007}

Os métodos apresentados na NBR 15527 (ABNT, 2007), bem como em seu anexo, possuem diferenças na indicação das mesmas variáveis, o que compromete o entendimento das fórmulas. Por exemplo, a variável "V" em alguns métodos é o volume do reservatório e, em outros, é o "volume de água aproveitável", ou "volume de água do reservatório", ou "volume de água da cisterna". Seria mais apropriado utilizar variáveis exclusivas para cada parâmetro, e a utilização de índices em algumas das variáveis, para diferenciar alguma característica específica. Um exemplo disso é o volume de água de chuva aproveitável, que poderia ser indicado como "V $\mathrm{V}_{\mathrm{AP}}$ " em vez de simplesmente "V", pois este pode ser confundindo com um método de dimensionamento em função do uso da nomenclatura "V" para os dimensionamentos no anexo da norma. Outra indicação de variável que pode provocar equívoco é o coeficente de aproveitamento do escoamento superficial (indicado na norma como $\mathrm{C}$, porém denominado neste artigo $\mathrm{C}_{\mathrm{AP}}$ ), o qual é resultante da multiplicação do coeficiente de escoamento 
superficial do material da área de captação (também indicado na norma como C), multiplicado por um fator de captação em função da eficiência do sistema existente. Talvez a indicação de "coeficiente de aproveitamento do escoamento superficial $\left(\mathrm{C}_{\mathrm{AP}}\right)$ " em vez de "coeficiente de escoamento superficial (C)" seria mais apropriada. Até mesmo a definição do volume do reservatório de água de chuva, que é a finalidade do anexo, fica comprometida quando, por exemplo, não aparece a indicação de seu cálculo no Método da Simulação e também quando no Método Prático Australiano está indicado que o volume do "tanque" escolhido será " $T$ ", mas também não está indicado como calcular esse “T”. Além disso, apenas nesse método existe denominação como tanque (T), que se entende ser o volume do reservatório de água de chuva, mas que nos demais métodos aparece como "V". Esses ajustes de nomenclatura e apresentação das equações são aqui sugeridos, pois facilitariam consideravelmente a utilização dos métodos apresentados na NBR 15527 (ABNT, 2007). Analisar a apresentação das variáveis nos métodos da NBR 15527 (ABNT, 2007) (e seu anexo) não foi o objetivo principal deste trabalho, mas conclui-se que uma revisão da norma para padronizar os termos e as variáveis seria conveniente, pois o entendimento dos métodos é prejudicado pela ambiguidade na nomenclatura de variáveis. Uma definição de nomenclatura específica aos sistemas de aproveitamento de água de chuva certamente é de valia para a comunidade técnica e científica, no sentido de evitar as associações dessas variáveis aos métodos de dimensionamento de sistemas de drenagem urbana ou outras obras hidráulicas.

Tanto na NBR 15527 (ABNT, 2007) como no Decreto Municipal 293/2006 existem outras considerações passíveis de melhorias, mas este artigo enfoca apenas os critérios relacionados especificamente ao dimensionamento de reservatórios. Vale ressaltar a importância da publicação daqueles documentos, que certamente iniciaram um processo importante para contribuir com a disseminação do uso de água de chuva em fins não potáveis e agora, após estes primeiros anos em circulação, podem ser objeto de melhorias.

\section{Conclusões}

Este estudo não foi conclusivo quanto à definição de qual seria o melhor método entre os avaliados neste artigo, pois os resultados não indicaram nenhum padrão constante e provavelmente cada caso terá seu método mais apropriado. Assim, salienta-se a importância de efetuar esse tipo de investigação comparativa, antes de optar por um ou outro método de dimensionamento. Os métodos que resultam em volumes maiores em geral, mas não necessariamente, atendem à condição de suprir a demanda por mais tempo ao longo do ano. Por outro lado, os métodos que resultam em menor volume apresentam menor custo do reservatório.

Dessa forma, a decisão final pelo método mais adequado pode ser baseada na comparação dos volumes obtidos, em sua viabilidade em termos de área disponível no local onde será construído o reservatório, e também no custo da construção do reservatório, o qual pode representar uma fração significativa do valor final do sistema. Aliado ao aspecto econômico, o aproveitamento de água de chuva para fins não potáveis, ao contribuir para a diminuição do consumo de água potável, resulta em ganho ambiental muito importante, e por isso deve ser estimulado. A qualidade da água de chuva coletada deve ser adequada ao atendimento das demandas, garantindo sempre a segurança sanitária dos usuários.

\section{Referências}

AGÊNCIA NACIONAL DE ÁGUAS. Conservação e Reúso de Água em Edificações. 2. ed. São Paulo: ANA; FIESP; SINDUSCON-SP, 2006. $152 \mathrm{p}$.

AGÊNCIA NACIONAL DE ÁGUAS. Disponibilidade e Demandas de Recursos Hídricos no Brasil. Brasília, DF: ANA, 2007. 123 p. Série Cadernos de Recursos Hídricos 2.

AGÊNCIA NACIONAL DE ÁGUAS. Conjuntura dos Recursos Hídricos no Brasil 2009. Brasília, DF: ANA, 2009. 204 p.

AMORIM, S. V.; PEREIRA, D. J. A. Estudo Comparativo dos Métodos de Dimensionamento para Reservatórios Utilizados em Aproveitamento de Água Pluvial. Ambiente Construído, Porto Alegre, v. 8, n. 2, p. 53-66, abr./jun. 2008.

ASSOCIAÇÃO BRASILEIRA DE NORMAS TÉCNICAS. NBR 10844: instalações prediais de águas pluviais. Rio de Janeiro, 1989.

ASSOCIAÇÃO BRASILEIRA DE NORMAS TÉCNICAS. NBR 15527: água de chuva: aproveitamento em áreas urbanas para fins não potáveis: requisitos. Rio de Janeiro, 2007.

CAMPOS, M. A. S. et al. Sistema de Aproveitamento de Água Pluvial: aspectos qualitativos e quantitativos. In: SIMPÓSIO NACIONAL DE SISTEMAS PREDIAIS, 10., 
2007, São Carlos. Anais... São Carlos: UFSCar, 2007. 1 CD-ROM.

COHIM, E; ALMEIDA, A. A. A.; KIPERSTOK, A. Captação Direta de Água de Chuva no Meio Urbano para Usos Não Potáveis. In: CONGRESSO BRASILEIRO DE ENGENHARIA SANITÁRIA E AMBIENTAL, 24., 2007, Belo Horizonte. Anais... Belo Horizonte, 2007.

COHIM, E.; GARCIA, A.; KIPERSTOK, A. Captação e Aproveitamento de Água de Chuvas: Dimensionamento de Reservatórios. In: SIMPÓSIO DE RECURSOS HÍDRICOS DO NORDESTE, 9., 2008, Salvador. Anais... Salvador, 2008.

COHIM, E.; OLIVEIRA, C. A Importância do Intervalo de Tempo na Simulação do Funcionamento de um Reservatório de Água de Telhado. In: CONGRESSO BRASILEIRO DE ENGENHARIA SANITÁRIA E AMBIENTAL, 25., 2009, Recife. Anais... Recife, 2009.

CHRISTAN, P. Análise das Exigências Impostas pelo Programa de Conservação e Uso Racional da Água nas Edificações - PURAE, Existentes na Cidade de Curitiba, Paraná. 2008. 105 f. Trabalho de Conclusão de Curso (Engenharia de Produção Civil) - Escola de Engenharia, Universidade Tecnológica Federal do Paraná, Curitiba, 2008.

CURITIBA. Lei Municipal $\mathbf{n}^{0} \mathbf{1 0 . 7 8 5}$, de 18 de setembro de 2003. Cria no município de Curitiba o Programa de Conservação e Uso Racional da Água nas Edificações. Curitiba, 18 de setembro de 2003.

CURITIBA. Decreto $\mathbf{n}^{\mathbf{0}}$ 293, de 22 de março de 2006. Regulamenta a Lei $n^{\circ} 10.785$ de 2003 e dispõe sobre os critérios do uso e conservação racional da água nas edificações e dá outras providências. Curitiba, 22 de março de 2006.

CURITIBA. Decreto n⿳ 212, de 29 de março de 2007. Aprova o Regulamento de Edificações do
Município de Curitiba.Curitiba, 29 de março de 2007.

GHISI, E.; CORDOVA, M. M.; ROCHA, V. L.

Netuno 2.1: Programa computacional.

Universidade Federal de Santa Catarina,

Departamento de Engenharia Civil. Disponível em: <http://www.labeee.ufsc.br/>. Acesso em: $14 \mathrm{dez}$. 2009.

MIERZWA, J. C. et al. Águas Pluviais: método de cálculo do reservatório e conceitos para um aproveitamento adequado. Revista de Gestão de Águas da América Latina, v. 4, p. 29-37, 2007.

MORUZZI, R. B.; OLIVEIRA, S. C.;

CARVALHO, G. Volume do Reservatório de Aproveitamento de Água Pluvial Baseado no Conceito do Balanço de Vazões para uma Residência Unifamiliar. Publicatio UEPG Ciências Exatas e da Terra, Ciências Agrárias e Engenharias, Ponta Grossa, v. 14, n. 3, p. 212217, dez. 2008.

TOMAZ, P. Aproveitamento de Água de Chuva: aproveitamento de água de chuva para áreas urbanas e fins não potáveis. 2 ed. São Paulo: Navegar, 2005. 180 p.

TOMAZ, P. Dúvida NBR 15527 [mensagem pessoal]. Mensagem recebida por <sbezerra@utfpr.edu.br>, em 28 mar. 2010.

\section{Agradecimentos}

Os autores agradecem sinceramente os comentários dos revisores, pois foram de extrema valia para a melhoria deste artigo. 